\title{
Humanity in the Digital Age: Cognitive, Social, Emotional, and Ethical Implications
}

\author{
Junko Yamamoto \\ Slippery Rock University of Pennsylvania, United States \\ Simeon Ananou \\ Salisbury University, United States
}

\begin{abstract}
Even though technology has brought great benefits to current society, there are also indications that the manner in which people use technology has undermined their humanity in some respects. In this article the authors frame human nature in terms of four dimensions: cognition, social interaction, emotion, and ethics. We argue that while basic human nature remains constant, the four dimensions are molded to some extent by interaction with our environment, particularly through the use of technology. As a powerful factor, we need to use technology in a way that human cognition, social interaction, emotion, and ethics are supported and not seriously disturbed by digital devices. Education can be a means of helping learners use technology in a positive way, minimizing its negative potential. This paper shows how people's choice and level of interaction with technology can allow them to live in harmony with technology. It also points to possible directions to teach healthy coexistence with technology. The suggestions include applying decision-making theory, increasing selfawareness, teaching academic honesty, and responding to problems with technology addiction through impulse control training and other programs.
\end{abstract}

Keywords: Digital age; Humanity; Cognition; Social interaction; Ethics; Digital citizenship

\section{Introduction}

E-book sales are booming. Young people can download e-books to kindle, iPad, or a phone and read them on the go, and the convenience makes e-books popular (Springen, 2012). Family and friends can catch up with inexpensive means of communication such as Skype, text message, and social media. There is no doubt that technology has become a big part of our lives. For example, the average time that North American children use technology for non-school related purpose is 8 hours per day (Rowan, 2010). It is not only the children of the United States that rely heavily on electronic devices: dependency on the Internet is a worldwide epidemic (Jiang \& Leung, 2012; Young, 2011; Young, Yue, \& Ying, 2011).

Naturally, a question arises: are we forming technology or is it forming us? Deragon (2011) examined the ways that technology influences humanity by addressing cognitive, social, and emotional implications. Those who spend long time on the Internet tend to be preoccupied with 
thoughts of online activities when they are offline (Caplan \& High, 2006). Technology "addicts" have difficulty limiting an online activity even when it interferes with work, study, financial wellbeing, or social functions (Turel, Serenko, \& Bontis, 2011; Turel, Serenko, \& Giles, 2011).

The correlation found in those studies, however, may not imply a causation. Buckner, Castille, and Sheets (2012) argue that those who tend to procrastinate and underperform at work may drive themselves to excessive Internet use and text messaging in order to cope with stress. In addition, those who have anxiety about face-to-face social interaction prefer online interaction because they feel that they are in better control of the exchange (Caplan, 2007).

While some perceive technology as the cause of the problem, others believe that technology only shows the problematic dispositions that people already possess. Some people allow technology to interfere with their lives, while others know when to turn a device off and get back to our social, family, academic, or economic activities. Some individuals take offense when witnessing a person checking Facebook or text messaging at the dinner table; others do not view such behavior as abnormal. In other words, not all respond to the technology environment in the same way.

Rosen (2012) suggests that those who are addicted to social networking may have a predisposition to be narcissistic, and social networking can escalate this tendency. Likewise, those who cannot have technology downtime may already tend to be impulsive and sensation seeking: such tendencies may contribute toward a dependency on technology. Children who lack self-regulation, for example, have the propensity to lack 'will power' as youths (Mischel et al., 2011), and are more likely to grow up into adults with less impulse control than children who demonstrate the selfcontrol (Casey et al., 2011). The lack of impulse control, therefore, may be the cause of overuse of electronic devices.

The preceding explanation does not mean that those who have difficulty getting offline should simply allow technology to control their lives. Since predispositions could be mediating factors, educators can consequently take steps to help learners understand how to live in harmony with tools in our environment. We can choose to use technology wisely and not let it destroy our social skills, cognitive ability, emotional awareness, and ethical values. Education in our time requires the creation and the delivery of instructional content as well as teaching and learning activities - but not confined to the four walls of a classroom. Instead, teaching and learning occurs in an environment for which the only conceivable boundaries are the proverbial ends of the Internet and the World Wide Web. There is thus a need to teach our children how to live and work in a new digital society (Ribble, 2009). Education then becomes critical even before the adoption and the use of modern day technologies.

Education is intended to make us more human by stimulating our creativity, cognitive abilities, and ethical values. Technology, however, when not always well orchestrated can distract the process of strengthening humanity, even sometimes diminishing our inquisitive abilities. Essentially, Information Communication Technologies (ICT) in education has engendered a new landscape that requires teachers and learners to newly examine impacts and strategies in each area of our lives: cognitive, emotional, social, and ethical. 
This paper explores how technology, a growing feature in our environment, has the potential to negatively influence humanity in terms of unchanging dimensions: cognitive, emotional, social and ethical. The authors will also show the potential role of education so the negative influence will be minimized.

\section{Influence of Technology}

This section reviews the four human dimensions, briefly tracing concerns about negative impacts. Deragon (2011) pointed out that technology influences humanity in cognitive, social and emotional areas. The authors of this article add one more: ethics. As the authors will mention later, these dimensions are often inseparable. However, examining one at a time makes it easier to understand a complicated subject, such as how technology interacts with us. Also, humanity is about our heredity, how we interact with our environment, and what we choose to do each day makes us who we are. The authors will not venture into discussing the entire topic of humanity. They will, instead, point out how human cognitions, socializations, emotions, and ethics are influenced by technology.

\section{Cognitive Implications}

Communication devices of the 21st century are often revered for their ability to facilitate instant written or oral conversations between individuals. It is not the devices, however, that provide instant response, but the individuals using them. The rise of technology-facilitated conversation appears to be conditioning individuals to expect instant gratification either by initiating the virtual interaction or by responding to it. We are left to wonder whether the instant nature of virtual interaction actually involved deep thinking or a simple reaction to the alert of the device?

While a face-to-face interaction may rely on body language tone in the delivery of a message, electronic communication cuts out those important cures, relying instead on quick and convenient access to news and events. Most electronic communication tools now make it even easier to offer a reaction without necessarily formulating one's thoughts. This is similar to face-to-face exchanges, but without the natural constraints of facing your partner in conversation. Electronic communication, it is impossible to take back a comment and have it erased from the person's memory. Electronic communication users, on the other hand, may assume it is acceptable to react immediately and retract later, simply by clicking a few buttons. In that sense, technology can be viewed as a powerful tool that allows people to communicate quickly, but not necessarily a tool for thoughtful communication under all circumstances. In theory, humans have the ability to think before sending, posting, or sharing content. Not all of us, however, choose to use the ability to sequence thoughts before action. When we forgo critical thinking, we risk alienating ourselves from what makes him human (Murphy \& Pardeck, 1986).

In addition, multitasking has become a predominant behavior among technology users. Watching TV and listening to music on a portable device while drafting an email and trying to respond to occasional text messages from friends, colleagues and families members - this scenario is becoming a common practice. Since the portable device might also be a telephone, a live call could 
very well be added to the multiple tasks already underway. A person's multitasking behavior is almost emerging as a badge of honor, while those who concentrate on one activity at a time could be viewed as being inefficient.

The real question about multi-taking one must ask is, "How well the human brain is able to process and assimilate multiple unrelated information and tasks?" After all, the brain can only process approximately seven spans of information in working memory (Miller, 1956). Rosen, Lim, Carrier, and Cheever (2011) found that low frequency of text messaging during a college class lecture did not have significant influence on learning, but the students who texted 16 times or more during a 30-minute video-taped lecture scored significantly lower on post-lecture test. Likewise, Kraushaar and Novak (2010) reported inverse relationship between course grades and non-course related multitasking during the lecture.

Polites and Karahanna (2012) argue that human behavior can be explained by individuals' habits. When one deviates from routine to learn something new, there is a 'cost of thinking.' If one is accustomed to responding quickly using email, text messaging, or tweet, it can require some hard work to change such habit. Nonetheless, thinking deeply while writing, or reflecting on the potential consequences before sending an electronic message, are good habits to develop in the digital age. However impressive the impact of ICT might appear in education, it requires a different cognitive effort from what might be experienced in non-technology mediated instruction. The traditional chalk and blackboard have been replaced with elaborate sets of technological solutions (audio visual apparatus, and instructional software) that are not always intuitive to all users. In fact, "navigating the world of information has become more complex and more difficult for adults, adolescents, and children" (Andrews \& Gann, 2011, p. 1).

The ability to adapt to socio-cultural changes such as the proliferation of ICTs for academic purposes requires a certain cognitive development that can be associated with biological age or with functional age. Verbal interaction with others, using universally acceptable to logics, propels one's cognitive ability (Piaget, 1959). This leads to a question regarding how verbal communication represented in quick tweet or text messaging while multitasking affects the habit and the process of formulating deep thinking.

\section{Social Implications}

Emails, video chats, and cell phones enable family and friends at a distance to communicate instantly and at low cost. However, when someone cannot stop checking work email or text messaging during family dinner or spends hours role-playing with an avatar in order to escape from real relationship, the dependency on electronic devices interferes with his or her normal life (Caplan \& High, 2011; Turel, Serenko, \& Bontis, 2011). The term 'addition' refers to this dependency and disruption of normal life.

Turkle (2011) laments that some people prefer text messaging to a phone conversation or face-toface interaction. One of her research subjects provided an anecdote that, when she went to interview a potential babysitter, her roommate texted her that she had a visitor, instead of going up to her room to tell her. Those who feel lonely and socially anxious in real life tend to fall into 
this category, because they spend more time communicating online than those who feel connected in a face-to-face environment (Bonetti, Campbell, \& Gilmore, 2010).

Becoming disconnected in a face-to-face relationship due to too much time spent online is not the only problem. Cyber connection itself can also infringe on our social functioning. The term 'flaming' has been used to describe abrasive statements made in cyberspace resulting in damage to a relationship. Negative comments can hurt others' feelings and aggravate conflict. It is easier, however, to heal the relationship face-to-face than online. "To work effectively on conflicts, the intervener needs a conceptual road map or conflict map that details why a conflict is occurring, identifies barriers to settlement, and indicate procedures to manage or resolve the dispute" (Moore, 2003, p. 58). It is hard to identify the source of conflict when tone of voice, body language, and facial expression are missing (Hsu, 2009; Turnage, 2008). This is often the case in text-based communication. For example, a comment that is meant to be a joke can be misinterpreted as an offensive remark. Moreover, email communication and text messages can be forwarded and be shared with others. This could result in other parties taking comments out of context and being upset.

Complaining via social media such as Facebook has the potential of having a bigger ripple effect because it gives the sense that one is being humiliated in front of a wide audience. Whether perceived or real, this sense of feeling disgraced in presence of a wide audience can have bigger impact on a person's social life than the same comments made face-to-face in front of a couple of people. Anonymity (Albin, 2012; Englander, 2008), accompanied by the inability to see facial cues and body language, makes cyber-bullying easier than offline bullying. The widespread occurrence of cyber aggression among children aging from 8 to 12 is correlated with loneliness offline (Schoffstall \& Cohen, 2011). Content sharing does have its positive side, such as advocating for social justice, community building, and professional exchange. Nonetheless, posting personal attacks on family, friends, co-workers, or supervisors on a public content-sharing site can have devastating impacts.

\section{Emotional implications}

Since social interaction can trigger emotional response (Hareli \& Rafaeli, 2008), influence on emotion is inevitable where there is social impact. Technology allows us to upload embarrassing videos and pictures of others on a public platform (Englander, Mills, \& McCoy, 2009) such as YouTube, Instagram and Facebook or it can be sent to hundreds of people with a mobile device. Moreover, such insults can remain permanent. Emotional scars from such humiliation can be extremely severe.

It is easier to make an unkind remark in an online environment, because one cannot see the emotional disturbance that the statement causes. People tend to care about each other's feelings when another person is in the same room. The digital age sometime offers a blurred sense of reality. When one cannot see another's facial interaction in an online environment, she may make a rude remark, forgetting there is a real person at the receiving end. 
The increased use of online social networks, text messaging, and email can collectively result in the decreased of face-to-face interaction. This may also result in less empathy. McQuellen (2003) argues that less time for face-to-face relationship causes the loss of interpersonal bonding. Konrath, O'Brien, and Hsing (2011) found that college students' ability to empathize dropped between 1979 and 2009.

One may ask, "Why worry about emotional impact on technology?" Emotion is, indeed, associated with better job performance. For example, preservice teachers who are better able to emotionally connect with their learners create and adjust instructional plans according to the learners' needs (Smith \& Place, 2011).

\section{Ethical implications}

In theory, education in the digital age can bring about a higher level of accessibility to information and education for people with geographic and social limitations. When properly designed and planned, blended and online education can appear as the best alternative to physical school infrastructure that is rather costly. At its best, online learning can provide a time and space for cross-cultural exchanges and collaborative learning in which student perspectives are accorded equal value (Rao, Eady, \& Edelen-Smith, 2011).

At the 2002 UNESCO-hosted Forum on the Impact of Open Courseware for Higher Education in Developing Countries, participants coined the term Open Educational Resources (OER), which was subsequently defined as: the open provision of educational resources, enabled by information and communication technologies, for consultation, use and adaptation by a community of users for noncommercial purposes (Johnstone, 2005). The OER movement aims to break down real or perceived barriers between the learner and the information. The OER movement also encourages and enables the sharing of content freely through the concept of open content in the digital age where content is not only openly available, but is also openly accessible and openly reusable.

The Internet has made great contribution to education. However, OER has added a layer of complexity to the notion that the abundance of content on the Internet makes it easier for student to engage in academically dishonest activities such as plagiarism. As a matter of principle, OER is contrary to "full-right reserve copyright, where reuse is always close to users, unless they seek and obtain permission and rights holders normally restrict the content's availability and accessibility in many different ways to avoid illegal use of material" (Lane, 2008, p. 158). Figure 1 illustrates the sources of plagiarized content in the digital age. 


\section{The Numbers: Plagiarism Sources}

Comes from social sharing sites such as Facebook and Answers.com

Come from homework and academic sites like medlibrary.org and nih.gov

Come from cheat sites such as appapers.com

Comes from news sites like The New York Times and the Huffington Post

Comes from encyclopedias, primarily Wikipedia

Comes from others sites

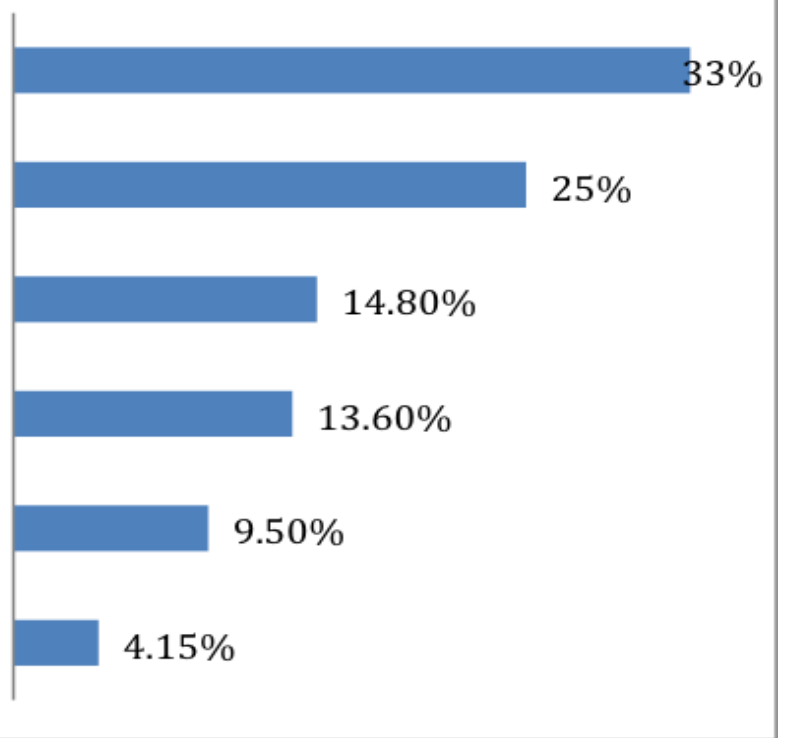

Figure 1. Percentage of plagiarism sources

(Adapted from "The new face of cheating," 2011, p.14)

Abundant information from the Internet makes plagiarism easy. While only a small portion of students admit giving into the temptation to copy others' work and submit it as their own, a large majority of students perceive cyber-plagiarism as a practice that is prevalent among their peers (Ananou, 2014). The degree of separation between perception and reality in cyber-plagiarism exposes the ethical gap that exists in academic honesty in the digital age.

\section{Framework for Humanity in the Digital Age}

Education is intended to make us more human by stimulating our creativity, cognitive abilities, and ethical values. Technology, however, when not always well orchestrated can distract the process of strengthening humanity, even sometimes diminishing our inquisitive abilities. The authors suggest the four elements of humanity: cognitive, ethical, social and emotional. These four components are closely related and they inter-act with another. They are inseparable, and they act as one. These elements of humanity have not changed; human nature has remained substantially the same throughout the ages. However, human development is influenced by environment. This section layers pre-technology elements, human nature, with the contemporary factor in the environment, digital devices. Figure 2 shows that one part is connected to other three parts. 


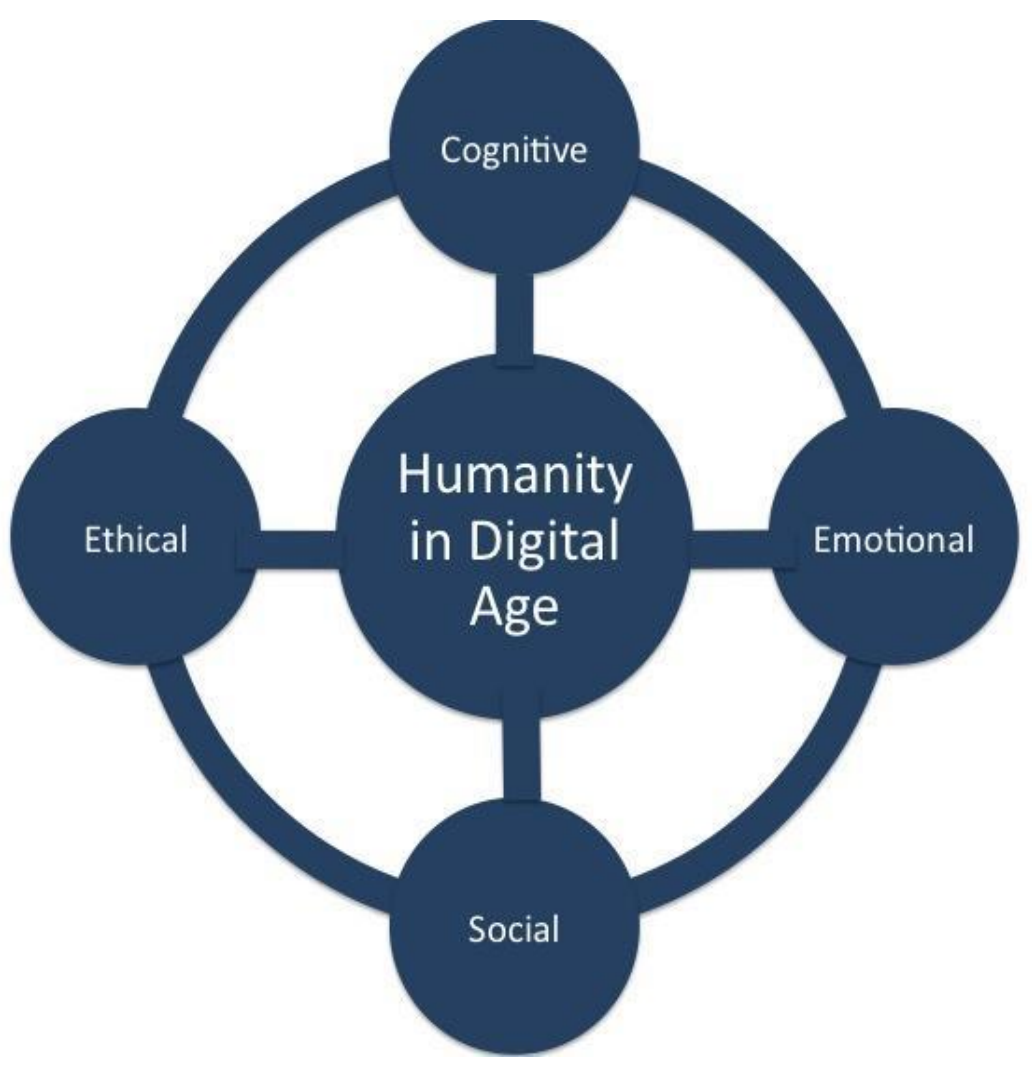

Figure 2. Framework for Humanity in the Digital Age

Humans develop emotion and learn values in a social context. For example, children learn emotional regulation strategies from parents (Bariola, Hughes, \& Gullone, 2011). Humans learn behaviors and values by observation. We adapt our behavior by imitating others, and what we do becomes part of our identification. We first pay attention to modeling, retain it, reproduce the behavior being observed, and then become motivated for another action (Bandura, 1986). If there is someone modeling an aggression, witnesses are more likely to mimic the behavior than those who do not watch the aggression (Bandura, 1973).

Emotional-social interaction can be observed in YouTube videos that teenagers post. Typing 'mean teachers' in the search box makes it evident that some teenagers utilize smart phones or other small video devices to capture angry teachers in their classrooms. They post the videos to YouTube, and get feedback. The videos can function as a trophy for getting attention from their peers. Classic operant conditioning experiments show that if people become motivated to behave in a certain way the behavior simply results in a reward. It appears that in some cases that all students in the classroom are aware that there is a hidden camera, and as a 'community,' they instigate a teacher until she becomes upset. When a group of students decide that this is a great entertainment, then they perceive it as positive. On the other hand, when an intervention occurs and they look at the same incident from the other person's perspective, a student may not participate in such inappropriate activity. Furthermore, if the students grow up in a home where compassions for others are taught, they may be less likely to find such videotaping entertaining. 
Emotion is closely related to cognition (Greenberg \& Safran, 1987). For example, emotion can influence attention to the task that is required. Positive emotions such as satisfaction, enthusiasm, and happiness, broadens the attention, but negative emotions such as anxiety, anger, disgust, guilt, and fear causes distraction (Lazar, Kaplan, Sternberg, \& Lubow, 2012). Complex thinking is done in neocortex, the newest part of the cerebral cortex of the brain. When a person faces anger or fear, amygdala, which is located in the limbic system, takes over the brain. Hence, it slows or incapacitates the activity of the thinking brain (Willis, 2007). Cognitive function is negatively correlated with amygdala activation (Okada et al., 2011). When one is under the influence of text messages, instant messaging, social media, or emails that make him or her upset, it is possible that that the ability to think rationally is undermined. If the individual responds while she is upset, it is possible that she sends a digital message that she would later regret sending.

On the other hand, cognition can influence emotional maturity. For example, suppose a boy has a tendency of sending out angry emails or text messages. If he recognizes that he has trouble controlling his emotion, and knows that it is hard to take back words that he puts in writing, he may be less likely to send electronic messages when he is angry. In order for such behavior management to occur, one must be ready to recognize her weaknesses or shortcomings. Humility, therefore, is a key ingredient for cognition-emotion link.

Upon being targeted to unfavorable comment, one can analyze how she is feeling. If she is upset, it is better not to respond. She can also refer to the other party's state of mind. If the other party's is normally a reasonable person, and the comment seems out of character, it is possible that the statements are jokes, or written under stress, or temporary anger. As the notion of amygdala sabotage shows, the other person is not likely to respond reasonably while he or she is under the influence of negative emotion. This means that she may say things that she will later wish to take back. In that case, determine if it is best to reply, ignore, wait, call, or talk face-to-face.

Chambers and Davis (2012) claim that the more easily a person can put himself in other person's shoes, the more empathetic he or she is. Therefore, one has to have the ability to see other's perspective in order to be empathetic. Empathy also involves self-knowledge. Those who lack humility, for example, may hurt other's feelings, recognize the emotional disturbance, but may also refuse to apologize. In a case presented in Lee's (2005) study, one participant in a flaming apologized. This not only caused another participant to apologize, but also reflect on his or her feelings, and potential behavioral modification that he or she would take more time to post in the future.

Self-knowledge, especially efficacy development, is also important so a person will not have to create avatars or fake identity to escape from self or to deceive others. There is 'real' person on ground. However, some individuals are obsessed with updating their profile in a cyber space to make it look more attractive, thinner, and smarter. Some spend hours interacting with others online with avatars (Turkle, 2011). Naturally, it is legitimate to ask, "Who really are we in a cyber space?" (Jones, 1997). Immordino-Yang (2011b) argues that self-awareness about affective change in a social context becomes the base for one's morality. In addition, social norms play a role in forming values (Immordino-Yang, 2011a). 


\section{Teaching Humanity in the Digital Age}

A few years ago, it was enough that educators monitor and facilitate the use of desktop technology located at a place at a given time. Mobilization of technology combined with increased use of technology has altered this norm. In fact, the ubiquitous access to technology is creating a sense of anxiety for parents who may be wondering how their children are using their mobile devices when unsupervised.

Education then becomes critical even before the adoption and the use of modern day technologies. Consequently, in addition to teaching their individual subject matter, educators are now expected to teach acceptable and responsible use of technology. Hence the authors recommend designing a framework of education in a manner capable of infusing humanity into the digital age.

How do we realize this framework within education? To assist educators, this section explores a few key ways these values can be further, through decision-making theory, technology addiction treatments, impulse control education, and teaching academic honesty.

\section{Decision Making Theory}

We all make choices. Good decision makers are not blindly manipulated with factors in environment (Berson et al., 2008). For example, upon hearing a notification sound for text messaging during a family dinner, one can decide to stop the conversation with the family to check the text message, or to check it later. A college student who is checking a social network site can choose to read selective messages from family and friends and then get back to his academic work. On the other hand, one who lacks the ability to prioritize what is more important in life can be absorbed into stimuli coming from an electronic device. The result would be constant disruption from their off-line life.

Parenting and social norm can influence decision-making regarding cyber ethics (DeWitt-Haffner \& Oxenford, 2001). Edwards (1954) argues that people make choices based on expected economic outcome. For example, students in teacher education programs may compare the pleasure of uploading and writing anything they want in a social networking site at the cost of lost employment opportunities when their online behaviors are viewed as inappropriate (Yamamoto, 2011).

"Post- millennial generations are very much given to entering into connections that are disclosing, spontaneous, multi-dimensional and reciprocal. They have very little interest in, or genuine commitment to, academic "objectivity" and the presumption that evaluative criteria or outcomes can be value free." (Gross, 2011, p 439). Olsen, Clough, \& Penning (2009) indicates that 56\% of elementary education majors in a Midwestern university had inappropriate content including excess drinking, vulgar language, and too much skin showing. Consequences of posting such material online, such as expulsion from student teaching or dismissal from a job, can be a part of career education. 


\section{Increasing Self-knowledge}

Self-reflection about how much time is being wasted in social media can lead a person to 'detoxify' from technology addiction. Radziwill (2010) kept her paper journal when she gave up social media. In her journal, she reflected that it was disappointing that she could not Tweet or Facebook to let all of her 'friends' know about her son's fifth birthday. However, she also pointed out that most of her connection in social media cares about her son's birthday: people who care would call.

In addition, technology users can recognize their power to make ethical decisions. Sometimes there is an ethical conflict that one needs to weigh pros and cons for each action. Regardless of which decision we make, we all need to live with our choices. Hill (2004) presented a case in which a person had to weigh consequences of an ethical dilemma and suggested the application of the decision-making model comprised of:

- Recognition - defining the problem

- Data gathering - identifying concepts and ideas

- Performing relevant tests - weighing and determining right vs. wrong

- Developing test prototypes - applying unitarian, deontological, justice-based, or virtue-based decision logics

- Producing solution - evaluating and reflecting on the outcome

Recognizing and celebrating personal integrity during the reflection phase can lead to more ethical choices in the future. Ethical choices eventually become a habit, and the habit can lead to the formation of personality.

\section{Steps to Recover from Technology Addiction}

Psychologists explored treatments for cases that one cannot stop overuse of the Internet or excess gaming, even when it destroys close relationship, career, or academic achievement (Young, Yue, \& Ling, 2011). Unfortunately, there are limited studies done for the cure for the Internet or video game addictions (Karim \& Chaudhri, 2012) because Internet addiction is still being explored (Turel, Serenko, \& Giles, 2011) since it was first researched and presented in 1996 (Young, Yue, and Ying, 1996).

Nonetheless, suggested treatments for technology addictions points to possible directions and further research. Rosen (2012) suggests that an addict can undergo planned breaks from technology. Perhaps planned breaks, paired with reflections, can be used to assist students who are suffering academically due to overuse of technology.

The first treatment model suggested for Internet addiction is cognitive behavioral therapy (CBT). Young (2011) argues that abstinence from the Internet is not realistic because our way of life depends heavily on the Internet. For instance, "a lawyer addicted to Internet pornography would need to learn to abstain from adult Web sites while still being able to access the Internet to conduct legal research and to e-mail clients" (p.305). 
The client who undergo CBT keep the daily Internet log including date and time, event, online activity, duration, and outcome. Once the problematic use is identified, the client may remove favorite bookmarks such as gaming sites, online porn, or gambling. In the next phase, the client work on his or her self-image. This is to assist the client with low self-esteem offline. During the next phase, Harm Reduction Therapy (HRT) is used to identify the factors that lead to Internet Addiction. It can be a relationship problem or a work-related stress. This therapy is used based on the belief that the addicts depend on the Internet to avoid coping with these issues.

Educators do not have the qualification to administer an addiction therapy. However, psychologists' works may be woven into an educational process to raise awareness and to prevent an addiction. Moreover, when college instructors become aware of a sign of Internet addiction, they can recommend on-campus counseling.

\section{Impulse Control Education}

Whether it is a flashing computer screen, the iPad notification sound for a new email, or a bell notifying the arrival of new text messaging, sometimes it takes a self-conscious effort not to react to it, and focus on something more important. Orienting one's mind to greater future gain can effectively reduce impulse (Cheng, Shein, \& Chiou, 2012). Educational implication can be creating a focus on delayed gratification, or what a learner can gain from resisting an urge to respond immediately.

Intervention in elementary school may be effective because children's executive functioning, that regulates cognitive and emotional development, may be related to frontal lobe development (Bernier, Carlson, and Whipple, 2010). Although children's home environment has a huge impact on their impulse control (Sharkey, Tirado-Strayer, Papachristos, and Raver, 2012), schools can also teach children self-regulation. For example, Hart et al. (2009) developed the curriculum targeted for increasing cognitive awareness in social and emotional skills. They implemented the unit for impulse control and problem solving with children in grades 3 and 4, and found that the treatment group's increase in knowledge of social and emotional skills are higher than the increase of knowledge in the control group. There is a missing link: there is no guarantee that children who are taught self-regulation at school will grow up to become adolescents and adults who can demonstrate self-regulation (e.g. refrain from text-messaging during a college class, limit personal use of the Internet while at work). The authors suggest a longitudinal study to find if there is a link.

\section{Teaching Academic Honesty}

Plagiarism can be prevented through proper education. One of the authors teaches a college-level instructional technology course. Digital ethics such as copyright, fair use, and plagiarism, are embedded in the course content. The university's academic integrity policy is included in the course syllabus and students verbalize what the policy means at the beginning of the semester. Students are reminded that if they use others' work, whether it is in text, image, audio, or video, they must create proper citation: using others' work without a proper citation, as a part of a class 
work would result in automatic failing grade for the assignment. The instructor also demonstrates how easy it is to catch plagiarism: a simple Google search can reveal the sources in seconds.

Students also practice how to cite different forms of media. For example, when the students create a Glog, an online poster, they create citations for pictures used on the Glog. Likewise, they make references to sound effects and images used in a digital movie in the form of 'credits' at the end of their production. Teaching about ethics, accompanied by the support to practice academic integrity, seem to be helpful.

In a recent study on academic honesty in the digital age, the other author suggested that universities should consider integrating cyber-plagiarism detection tools into the curriculum very early one. The study concluded that, "by making these technologies available to students not as a punitive measure, universities could be targeting the need for students to become both responsible digital citizens and digital scholars" (Ananou, 2014, p. 142).

\section{Conclusion}

There is no doubt that technology has impacted our lives in many ways. However, we can all choose to let it control us or to be in charge of our own behavior. While some of us become addicted to various behavior patterns such as social media, text messaging, gaming, or online bidding, others do not allow technology to take over our lives. Also, educators can teach students about the consequences for academic dishonesty and help form the habit for properly citing their sources. Pre-disposition to become a technology-addict have been discussed in this paper. In addition, decision-making theory, technology addiction treatment, impulse control education, and education for academic honesty were mentioned as references for educators to teach how to lead a healthy life surrounded by technology.

The ethical and social elements make up two of the four components of the recommended framework. These components are already converted into educational materials by Ribble (2011) with the term "digital citizenship." His instructional plans and assessments to teach young adults on topics such as communication, etiquette, and rights and responsibilities using digital media may easily be adapted and implemented in a classroom.

Likewise, Common Sense Media (https://www.commonsensemedia.org/) has developed a wide range of resources for educators and parents. Educators can download videos and the corresponding lesson plans that are interesting to young adults. The authors recommend that educators use these resources. Additionally, educators and administrators alike should consider the development of relevant frameworks in the future promote a responsible use of technology.

\section{References}

Albin, K. A. (2012). Bullies in a wired world: The impact of cyberspace victimization on adolescent mental health and the need for cyberbullying legislation in Ohio. Journal of Law \& Health, 25(1), 153-188. 
Ananou, S. T. (2014). Academic honesty in the digital age. (Doctoral dissertation, Indiana University of Pennsylvania). Retrieved on 18 June 2014 from http://pqdtopen.proquest. com/ doc/1524251772.html?FMT=Al

Andrews, S., \& Gann, L. (2011). An information literacy progression. School Library Monthly, 28(2), 21-23.

Ashman, A. F. \& Conway, R. N. F. (2002). Introduction to cognitive education: Theory and applications. London: Routledge.

Bandura, A. (1973). Agression: A social learning analysis. Englewood Cliffs, NJ: Prentice-Hall.

Bandura, A. (1986). Social foundations of thought and action: A social cognitive theory. Englewood Cliffs, NJ: Prencice-Hall.

Bariola, E., Hughes, E. K., \& Gullone, E. (2011). Relationships between parent and child emotion regulation strategy use: A brief report. Journal of Child \& Family Studies, 21(3), 443-448.

Bernier, A., Carlson, S. M., Whipple, N. (2010). From external regulation to self-regulation: Early parenting precursors of young children's executive functioning. Child Development, 81(1), 326-339.

Berson, I. R. Berson, M. J., Desai, S., Falls, D., \& Fenaughty, J. (2008). An analysis of electronic media to prepare children for safe and ethical practices in digital environments. Contemporary Issues in Technology and Teacher Education, 8(3), 222-243.

Bonetti, L., Campbell, M. A., \& Gilmore, L. (2010). The relationship of loneliness and social anxiety with children's and adolescents' online communication. Cyberpsychology, Behavior and Social Networking, 13(3), 279-285. doi: 10.1089/cyber.2009.0215

Buckner, J. E., Castille, C. M, \& Sheets, T. L. (2012). The five factor model of personality and employees' excessive use of technology. Computers in Human Behavior, 28(5), 1947-1953. Retrieved from http://www.sciencedirect.com/science/article/pii/S0747563212001422

Caplan, S. E. (2007). Relations among loneliness, social anxiety, and problematic Internet use. Cyber Psychology and Behavior, 10(2), 234-242. doi: 10.1089/cpb.2006.9963

Caplan, S. E. \& High, A. C. (2006). Beyond excessive use: The interaction between cognitive and behavioral symptoms of problematic Internet use. Communication Research Report, 23(4), 265-271.

Caplan, S. E. \& High, A. C. (2011). Online social interaction, psychosocial well-being, and problematic internet use. In K. S. Young, \& C. N Abreu (Eds.), Internet addiction: A handbook and guide to evaluation and treatment (pp. 35-53). Hoboken, NJ: John Wiley \& Sons.

Casey, B. J., Somerville, L. H., Gotlib, I. H., Ayduk, O., Franklin, N. T., Askren, M. K., Jonides, J., Mischel, W., \& Shoda, Y. (2011). Behavioral and neural correlates of delay of gratification 40 years later. Proceedings of the National Academy of Sciences of the United States of America, 108(36). Retrieved on 18 June 2014 from http://www.pnas.org/content/108/36/14998.full. pdf + html

Chambers, J. R. \& Davis, M. H. (2012). Perspective-taking and empathy: Ease of self-simulation as a heuristic for inferring empathic feelings. Social Cognition, 30(2), 153-180. 
Cheng, Y., Shein, P. P., \& Chiou, W. (2012). Escaping the impulse to immediate gratification: The prospect concept promotes a future-oriented mindset, prompting an inclination towards delayed gratification. British Journal of Psychology, 103, 129-141. doi: 10.1111/j.20448295.2011.02067.x

Deragon, J. (January, 2011). The influence of technology on humanity. Retrieved on 18 June 2014 from The Relationship Economy website: http://www.relationshipeconomy.com/2011/ 01/technologys-influence-over-humanity/

DeWitt-Heffner, J. \& Oxenford, C. (2001, November). Defining the limits: Cyber ethics. Paper presented at the National Convention of the Association for Educational Communications and Technology. Atlanta, GA.

Edwards, W. (1954). The theory of decision making. Psychological Bulletin, 51(4), 380-411.

Englander, E. (2008). Cyberbullying \& bullying in Massachusetts: Frequency \& motivations. Retrieved on 18 June 2014 from http://webhost.bridgew.edu/marc/MARC\%20findings\%20 summary \%202008.pdf

Englander, E., Mills, E. \& McCoy, M. (2009) Cyberbullying and information exposure: Usergenerated content in post-secondary education. International Journal of Contemporary Sociology, 46(2), 213-230.

Greenberg, L. S. \& Safran, J. D. (1987). Emotion in psychotherapy. New York, NY: The Guilford Press.

Gross, E. R. (2011). Clashing values: Contemporary views about cheating and plagiarism compared to traditional beliefs and practices. Education, 132(2), 435-440.

Hart, S. R., Dowdy, E., Eklund, K., Renshaw, T. L., Jimerson, S. R., Jones, C., \& Earhart, J. (2009). A controlled study assessing the effects of the impulse control and problem solving unit of the Second Step curriculum. The California School Psychologist, 14, 105-110.

Hareli, S. \& Rafaeli, A. (2008). Emotion cycles: On the social influence of emotions in organizations. Research in Organizational Behavior, 28, 35-59.

Hill, R. B. (2004). Closing thought about ethics for citizenship in a technological world. In R. Hill (Ed.), Ethics for citizenship in a technological world (pp.267-276). New York: Glencoe McGraw-Hill.

Hsu, T. (2009). Flaming issues in online courses. International Journal of Learning, 15(10), 65-70.

Immordino-Yang, M. H. (2011a). Implications of affective and social neuroscience for educational theory. Educational Philosophy and Theory, 43(1), 98-103.

Immordino-Yang, M. H. (2011b). Me, my "self" and you: Neuropsychological relations between social emotion, self-awareness, and morality. Emotion Review, 3, 313-315, doi: $10.1177 / 1754073911402391$

Jiang, Q. \& Leung, L. (2012). Effects of individual differences, awareness-knowledge, and acceptance of Internet addiction as a health risk on willingness to change Internet habits. Social Science Computer Review, 30(2), 170-183. doi: 10.1177/0894439311398440

Johnstone, S. M. (2005). Open educational resources serve the world. Educause Quarterly Review, 3, 15-18. 
Jones, S. G. (1997). The Internet and its social landscape. In S. G. Jones (Ed.). Virtual culture (pp.735). Thousand Oaks, CA: Sage Publications.

Karim, R. \& Chaudhri, P. (2012). Behavioral addictions: An overview. Journal of Psychoactive Drugs, 44(1), 5-17. doi: 10.1080/02791072.2012.662859

Konrath, S. H., O'Brien, E. H., \& Hsing, C. (2011). Konrath, S. H., O'Brien, E. H., \& Hsing, C. (2011). Changes in dispositional empathy in American college students over time: A meta-analysis. Personality and Social Psychology Review, 15(2), 180-198.

Kraushaar, J. M. \& Novak, D. C. (2010). Examining the effects of student multitasking with laptops during the lecture. Journal of Information Systems Education, 21(2), 241-251.

Lane, A. (2008). Who puts the education into open educational content? In. R. Katz (Ed.), The tower and the cloud: Higher education in the age of cloud computing (pp.158-169). Washington D.C.: Educause.

Lazar, J., Kaplan, O., Sternberg, T., \& Lubow, R. E. (2012). Positive and negative affect produce opposing task-irrelevant stimulus preexposure effects. Emotion, 12(3), 591-604.

Lee, H. (2005). Behavioral strategies for dealing with flaming in an online forum. The Sociological Quarterly, 46(2), 385-403.

McQuillen, J. S. (2003). Education, 123(3), 616-623.

Miller, G. A. (1956). The magical number seven, plus or minus two: Some limits on our capacity for processing information. Psychological Review, 63(2), 81-97.

Mischel, W., Ayduk., O., Berman, M. G., Casey., B. J., Gotlib., I H., Jonides, J., Kross, E., Teslovich., T., Wilson, N. L., Zayas, V., \& Shoda, Y. (2011). 'Willpower' over the life span: Decomposing selfregulation. Social Cognitive \& Affective Neuroscience, 6, 252-256. doi: 10.1093/scan/nsq081

Moore, C. (2003). The mediation process. San Fransisco: Jossey-Bass.

Murphy, J. W., \& Pardeck, J. T. (1986). Introduction. In J. W. Murphy \& J. T. Pardeck (Eds.), Technology and human productivity (pp. xiii - xx). New York, NY: Quorum Books.

Okada, G., Okamoto, Y., Kunisato, Y., Aoyama, S., Nishiyama, Y., Yoshimura, S., Onoda, K., Toki, S., Yamashita, H., \& Yamawaki, S. (2011). The effect of negative and positive emotionality on associative memory: An fMRI study. PLoS ONE, 6(9), e24862. doi: 10.1371/journal.phone.0024862

Piaget, J. (1959). The language and thought of the child (3rd ed.). New York, NY: The Humanities Press.

Piaget, J. (1973). To understand is to invent: The future of education. New York, NY: Grossman Publishers.

Piaget, J. (1977). The development of thought: Equilibration of cognitive structures (R. Rsoin, Trans.). New York, NY: Viking Press.

Polites, G. L., \& Karahanna E. (2012). Shackled to the status quo: The inhibiting effects of incumbent system habit, switching costs, and inertia on new system acceptance. MIS Quarterly, 36(1), 21-42. 
Radziwill, N. (2010). Disconnected: Technology addiction \& the search for authenticity in virtual life. [Kindle version]. Retrieved on 18 June 2014 from http://www.amazon.com/DisconnectedTechnology-Addiction-Authenticity-ebook/dp/B0041T4JBM/ref=tmm_kin_title_0?ie=UTF8 \& $m=A G 56 T W V U 5 X W C 2$

Rao, K., Eady, M., \& Edelen-Smith, P. (2011). Creating virtual classrooms for rural and remote communities. Phi Delta Kappan, 92(6), 22-27.

Ribble, M. (2009). Raising a digital child. Washington D.C.: International Society for Technology in Education.

Ribble, M. (2011). Digital citizenship in schools (2nd ed.). Eugene, Oregon: The International Society for Technology in Education.

Rosen, L. D. (2012). iDisorder: understanding our obsession with technology and overcoming its hold on us [Kindle version]. Retrieved on 18 June 2014 from https://kindle.amazon.com/ work/idisorder-understanding-obsession-technology-overcoming/B005NTF0OY/ 0230117570

Rosen, L. D., Lim, A. F., Carrier, L. M., \& Cheever, N. A. (2011). An empirical examination of the educational impact of text message-induced task switching in the classroom: Educational implications and strategies to enhance learning. Psicologia Educativa, 17(2), 163-177.

Rowan, C. (2010). Unplug - don't drug: A critical look at the influence of technology on child behavior with an alternative way of responding other than evaluation and drugging. Ethical Human Psychology and Psychiatry, 12(1), 60-68. doi: 10.1891/1559-4343.12.1.60

Schoffstall, C. L. \& Cohen, R. (2011). Cyber aggression: The relations between online offenders and offline social competence. Social Development, 20(3), 587-604. doi: 10.1111/j.14679507.2011.00609.x

Sharkey, P. T., Tirado-Strayer, N., Parachristos, A. V., \& Raver, C. (2012). The effect of local violence on children's attention and impulse control. American Journal of Public Health, 102(12), 2287-2293. doi:10.2105/AJPH.2012.300789

Smith, A. T. \& Place, N. A. (2011). Fostering teaching and learning through an inquiry-based literacy methods course. The New Educator, 7(4), 305-324.

Springen, K. (2012). Are teens embracing e-books? Publishers Weekly, 259(8), 20-23.

The new face of cheating. (2011, Back to School). Scholastic Administrator, 11(1). 14.

Turel, O., Serenko, A., \& Bontis, N. (2011). Family and work-related consequences of addiction to organizational pervasive technologies. Information \& Management, 48, 88-95.

Turel, O., Serenko, A., \& Giles, P. (2011). Integrating technology addiction and use: An empirical investigation of online auction uses. MIS Quarterly, 35(4), 1043-1061.

Turke, S. (2011). Alone together: Why we expect more from technology and less from each other. New York: Basic Books.

Turnage, A. K. (2008). Email flaming behavior and organizational conflict. Journal of ComputerMediated Communication, 13(1), 43-59. doi: 10.1111/j.1083-6101.2007.00385.x

Wills, J. (2007). The gully in the 'brain glitch' theory. Educational Leadership, 64(5), 68-73. 
Yamamoto, J. (2011). The muddy field of social networking: Implications for teacher educators. In T. Bastiaens \& M. Ebner (Eds.), Proceedings of World Conference on Educational Multimedia, Hypermedia and Telecommunications (pp. 3369-3373). Chesapeake, VA: AACE.

Young, K. S. (2011). CBT-IA: The first treatment model for Internet addiction. Journal of Cognitive Psychotherapy, 25(4), 304-312.

Young, K. S., Yue, X. D. \& Ying, L. (2011). Prevalence estimates and etiologic models of Internet addiction. In K. S. Young \& C. N. de Abreau (Eds.), Internet addiction (pp. 3-17). Hoboken, N. J.: John Wiley \& Sons.

Correspondence: Junko Yamamoto, Associate Professor, Department of Secondary Education/ Foundations of Education, Slippery Rock University of Pennsylvania, Slippery Rock, PA, United States 